\title{
The embedded carbon footprint of urban households in China and its evolution
}

\author{
$\underline{\text { Dingtao Zhao }}^{1}$, Jin Fan $^{1}$, Xiumei Guo ${ }^{2}$, Dora Marinova ${ }^{2}$, Yanrui Wu ${ }^{3}$ \\ ${ }^{1}$ Management School, University of Science and Technology of China \\ ${ }^{2}$ Curtin University Sustainability Policy (CUSP) Institute, Curtin University \\ ${ }^{3}$ Business School, University of Western Australia
}

\begin{abstract}
This paper explores the embedded carbon footprint (ECF) that is associated with various activities of urban households in China. An input-output model for carbon emissions is constructed. Based on urban household data for the period of 2003-2009, we calculate individual ECF and analyze its structural evolution. The results of this analysis show that the total ECF emission intensity increases when an individual's consumption is higher than 10000 yuan (which is the turning point). This implies that emission intensity increases with a luxury lifestyle whereas it is lower for lower-income households. As income continues to increase, China will continue to remain on a high carbon track. We hence suggest that, with increasing urban wealth there is a need for better policies, management and behavioural change in order to reduce the carbon emissions of households. This study provides some policy suggestions about establishing a carbon quota system to guide individual consumption.
\end{abstract}

Keywords: $\quad$ Input-output model of carbon emissions, Life style, Urban residents, Carbon quota system 


\section{INTRODUCTION}

As the top global greenhouse gas emitter since 2007, reducing environmental pressure is a major concern for China. According to Lenzen and Shauna (2001), the main factor causing carbon dioxide $\left(\mathrm{CO}_{2}\right)$ emissions to grow is the increased per-capita consumption, which offsets technological improvements and structural changes. A sustainable society cannot be achieved without a fundamental change in consumption patterns (Rood et al. 2003) and households' activities (Druckman and Jackson 2009). This paper is focused exclusively on $\mathrm{CO}_{2}$ emissions as the primary indicator of the environmental externality. The study provides an overview of the embedded carbon footprint (ECF) of urban households in China. Section 1 reviews existing literature and Section 3 introduces the methodology of this study. Trends in ECF are presented in Section 4. Finally, we synthesize the salient findings and comment on their relevance for policy-makers.

\section{LITERATURE REVIEW}

The use of fossil energy resources is one of the main causes for $\mathrm{CO}_{2}$ emissions. One way of reducing emissions is to change consumer demand. Households not only use direct energy in the form of gas, electricity and petrol, but they also use indirect energy embedded in the production, transportation and disposal of consumer goods and services. We define Embedded Carbon Footprints (ECF) as the $\mathrm{CO}_{2}$ emissions from the whole lifecycle of household products and services including manufacturing and disposal. Indirect energy use can be regarded as important as direct energy use (Lenzen et al. 2004). In Europe, approximately half of the average household energy use is estimated to be indirect energy use (Reinders et al. 2003). The indirect energy requirement is more difficult to address and has not yet been a reduction subject (Benders et al. 2006). Indirect energy use may be affected by the behaviors and decisions of producers and distributors, but also by changing consumer behaviors (Abrahamse and Steg 2009).

Analysing the environmental impact of household consumption remains an important topic in sustainability research. This includes studies by Reinders et al. (2003) on energy requirements of EU households; Lenzen et al.'s (2004) input-output analysis of Sydney households; Druckman and Jackson's (2009) UK household demand model and Weber and Matthews' (2008) analysis of the American household carbon footprint. Benders et al. (2006) developed a web tool to assist households in energy conservation but despite savings in direct energy use, the reduction in indirect energy was not significant. Indirect energy use was positively associated with income and household size, and indirect energy savings could be significantly explained by treatment, attitude and perceived behavioral control (Abrahamse and Steg 2009). Households are an important group for energy conservation. There hasn't been a lot of research on the ECF of Chinese urban residents. In order to shed light on the link between satisfaction of human needs/desires and $\mathrm{CO}_{2}$ emissions, and to understand the scale of required reductions, we ask: What are the current trends in $\mathrm{CO}_{2}$ emissions in China and to what extent is coupling occurring between household expenditure and $\mathrm{CO}_{2}$ emissions.

\section{METHODOLOGY AND DATA SOURCES}

There are two main alternatives in estimating ECF. One is based on the estimates of "apparent consumption" of each type of energy resource along the line of the methodology proposed by Wackernagel and Rees (1996). The other proposed by Bicknell et al. (1998) is based on the monetary values of products that are delivered for domestic demand with the information recorded in an input-output (IO) table. The former uses the amounts of energy in a defined economy, not in the products consumed by its population (Ferng 2001). When an economy is a big exporter of finished products produced using great amounts of imported resources, the deficiency in such calculations is apparent. When consumer activities are linked to the IO patterns in the economy, and hence to the accompanying energy requirements (Benders et al. 2006), the assessment is better. This method can be applied to different populations (Bicknell et al. 1998). The product flows recorded in an IO table and the value of the associated energy for domestic consumption can be approximately traced.

Bicknell et al. (1998) were the first to propose generalized IO analysis as a method for calculating the ecological footprint. In recent years there have been other studies using a similar approach (Ferng 2001, Druckman and Jackson 2009). Given that the ECF focus is to capture the total $\mathrm{CO}_{2}$ emissions embodied in final consumption in an economy, input-output would seem to be a good accounting framework. In this study we use a closed-economy framework where imports are exogenously given and the direct and indirect $\mathrm{CO}_{2}$ emissions coefficients of these imports are assumed to be identical to those in China. No distinction is made for the origins of the intermediate inputs used by the producing sectors in the exporting countries. We explore the ECF amounts used to support various different activities that make up modern lifestyle and we attribute ECF to functional uses: household, food and catering, clothing and footwear, health and hygiene, recreation 
and leisure, education, communications and commuting (Weber and Matthews 2008, Druckman and Jackson 2009). The total ECF is:

$$
E C F_{\text {total }}=\sum_{i=1}^{M} \sum_{j=1}^{N}\left\{\sum_{j}\left[\operatorname{diag}(B)(I-A)^{-1}\right]\right\} Y_{i j}
$$

where $B$ is a $1 \mathrm{xN}$ vector, with diagonal elements $b_{j}$ representing the average $\mathrm{CO} 2$ emissions per monetary unit of gross output for each stage in sector $j$. A is the direct requirements (or input-output coefficients) matrix; $Y$ is final demands; $\sum j\left[\operatorname{diag}(B)(I-A)^{-1}\right]$ is the emissions multiplier of sector $j$, where $i=1, \ldots, \mathrm{M}$, for consumption category $i$, where $j=1, \ldots, \mathrm{N}$, for each economic sector $j$.

The IPCC published its 2006 Guidelines for National Greenhouse Gas Inventories. These and many more greenhouse gas emission factors can be found on IPCC's Emission Factor Database. The conversion between electricity usage and $\mathrm{CO}_{2}$ emissions is considerably more complicated than the conversion between fossil fuels usage and emissions. The average $\mathrm{CO}_{2}$ emission factors for electricity generation can be estimated as:

$$
\rho_{9}=\frac{\sum_{j=1}^{3} \sum_{i=1}^{8} \omega_{i} \rho_{i}}{Q}
$$

where $\omega_{l}$ is the use of fossil fuels by power plants, such as by thermal power plants, hydropower plants and nuclear power plants; $\rho_{l}$ is the emission factors for fossil fuels, $Q$ is power generation.

The $\mathrm{CO}_{2}$ emissions in economic sector $j$ is

$$
\Phi_{j}=\frac{\pi_{j}}{\sum_{i=1}^{9} q_{i j} \varphi_{i} / \lambda_{i}}\left(\sum_{i=1}^{8} q_{i j} \rho_{i}+q_{9 j} \rho_{9} \lambda_{9}\right)
$$

where $\pi_{i}$ is total energy consumption by sector $j, \varphi$ is conversion factors from physical unit to coal equivalent, $q_{i} j$ is final energy consumption by sector $j, \lambda$ is the efficiency of energy transformation. The average $\mathrm{CO}_{2}$ emissions per unit of gross output in sector $j \quad b_{j}=\frac{\Phi_{j}}{X_{j}}$ is $\quad$ (4) where $X_{j}$ is gross output in sector j.

The $\mathrm{CO}_{2}$ emission factors for coal, coke, crude oil, gasoline, kerosene, diesel, fuel oil and natural gas are in IPCC's Emission Factor Database. NBSC (2007) gives the consumption of total energy by economic sector, conversion factors from physical unit to coal equivalent, final energy consumption by sector and the efficiency of energy transformation. The latest estimates show that global greenhouse gas emissions of urban activities accounted for more than $67 \%$ (IEA 2008). For household expenditure we use data from NBSC (2003-2009) and China's IO statistics are available for the year 2005.

\section{RESULTS AND DISCUSSION}

Figure 1 shows the current trends in China's $\mathrm{CO}_{2}$ emissions. After a slight decrease between 1997 and 2000, the emissions steadily increased with 2005 levels $48 \%$ higher than those in 1995. Due to the replacement of small generation units with large ones, emissions decreased at a faster rate than energy use in the late 1990s, and remained below 1995 levels until 2002. However since then they have increased at about the same rate as energy use. Emissions intensity has a downward trend, from 2.65 tons of $\mathrm{CO}_{2} /$ ton of standard coal in 1995 to 2.38 in 2005. Hence China's energy efficiency has constantly optimized, but its gross $\mathrm{CO}_{2}$ emissions have an upward trend, consistent with the "Jevons Paradox". The technical efficiency improvement in energy use leads to slightly higher energy consumption if it is not accompanied by adjustments in lifestyle (Adua 2010). Therefore, the growth of $\mathrm{CO}_{2}$ emissions should be attributed to the final consumption (including export) growth, which is in line with the conclusion that the main factor driving emissions growth is the increase of per-capita consumption (Lenzen and Shauna 2001).

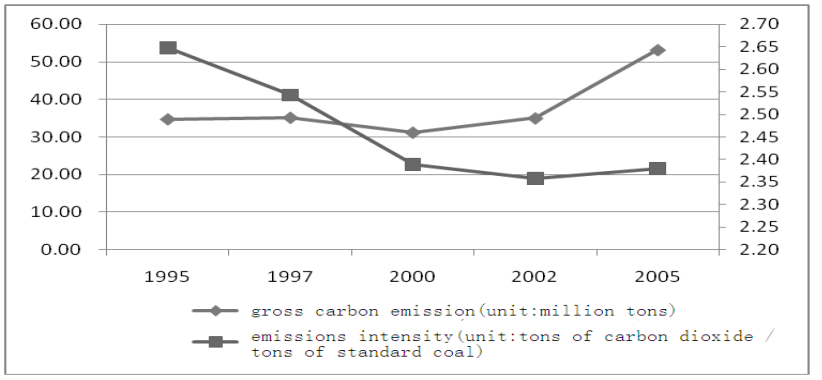

Figure 1. $\mathrm{CO}_{2}$ Emission Trends, China 1995-2005

As would be expected, different consumption categories have very different shares of both expenditure and ECF. On the broadest scale, average urban household consumption totaled $¥ 7942$ in 2005 and resulted in $2007 \mathrm{~kg}$ of CO2, for an average CO2 intensity of consumption of about $0.25 \mathrm{~kg} \mathrm{CO} 2 /$. Some consumption categories, such as education, recreation and food have much lower intensities while others, such as housing and personal transport, have much higher intensities. Figure 2 shows this distribution of ECFs by each individual category consumption shares against total annual expenditure. Several interesting trends can be 
noted. Lower income and expenditure groups tend to generate a larger share of their $\mathrm{CO}_{2}$ from what could be seen as 'necessities'-food. While the ECF from this category grows with increased expenditure, there is a diminishing returns effect, and the share of ECF associated with this category drops as other consumption categories become more important: housing, recreation and personal transport. It is important to note that the most $\mathrm{CO}_{2}$ intensive categories (transport and housing) are

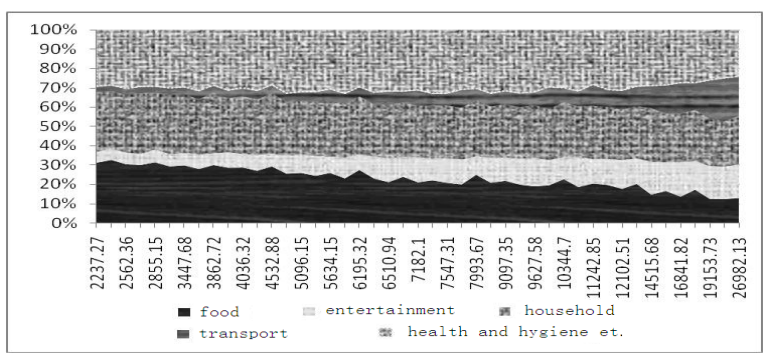

Figure 2. $\mathrm{CO}_{2}$ Emissions of Chinese Households precisely the items which make up the bulk of high-income consumption bundle.

The ECF and its shares are closely related to consumer expenditure. With consumption expenditure per capita increasing 11 times from $¥ 2,200$ to $¥ 27,000$, ECF per capita increases 15 times from 540 to $7000 \mathrm{~kg}$. Hence ECF per capita grows faster than consumption expenditure, and emissions intensity increases with rising expenditure. When consumption expenditure is less than $¥ 6000$, the ECF structure is relatively stable; but from around $¥ 8000$, the ECF associated with personal transport and recreation start to rise.

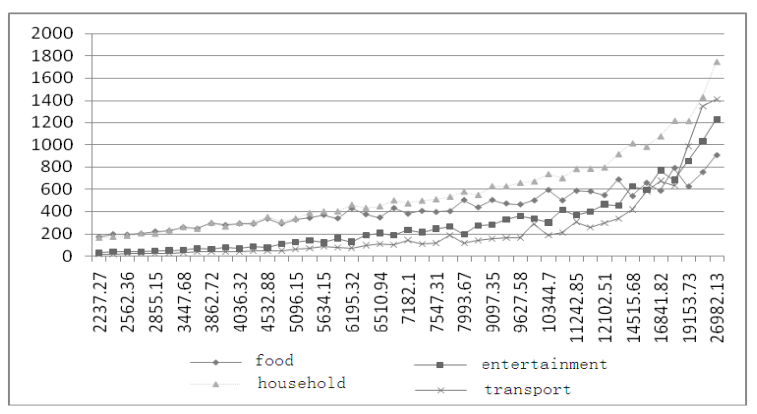

Figure 3. Absolute Amounts of $\mathrm{CO}_{2}$ Emissions

- Food ECF: As the level of consumer expenditure rises from $¥ 2,200$ to $¥ 27,000$, the proportion of food ECF becomes smaller (Figure 2), from 30\% to 13\%. In absolute terms (Figure 3), the food ECF is relatively stable, which shows that the food-type ECF is survival emissions.

- Housing ECF: Housing dominates the ECF, ranging between 24 and 31\% of the overall ECF (Figure 2). In absolute terms, it increases rapidly with the increase in consumption level. An explanation for this is the urban housing system reform which canceled the in-kind welfare housing allocation and implemented housing commercialization and monetization. With the improvement of living standards in China, buying a house has become a consumption hot spot.

- Other ECFs: The shares of transport, leisure and entertainment ECF increase with consumption expansion, from $3 \%$ and $6 \%$ to $20 \%$ and $18 \%$; rising rapidly when consumption expenditure per capita reaches $¥ 8000$. The shares of health and hygiene, clothing, education and communication ECFs are small and stable.

To describe the evolution of Chinese urban residents' ECF, the ECF function to expenditure is constructed using formula (5), including a dummy variable. When the expenditure is lower than the value of the inflection point, the dummy variable is set to 0 , otherwise to 1 . By testing whether the product of the dummy variable and expenditure is significant, we can determine the existence of an inflexion point.

$E C F=\alpha+\beta D+b_{1} D x+b_{2} x+\varepsilon$

(5) where $\mathrm{D}$ is dummy variable, $x$ is consumption expenditure.

Table 1. Regression Results for ECF per Capita $(* \mathrm{p}<.05)$

\begin{tabular}{|c|c|c|c|c|c|}
\hline & \multicolumn{2}{|c|}{$b_{1}$} & \multicolumn{2}{|c|}{$b_{2}$} & \multirow{2}{*}{$\begin{array}{l}\text { Adjusted } \\
\text { R Square }\end{array}$} \\
\hline & $\begin{array}{l}\text { Unstandardized } \\
\text { Coefficients }\end{array}$ & Sig. & $\begin{array}{l}\text { Unstandardized } \\
\text { Coefficients }\end{array}$ & Sig. & \\
\hline ECF & $0.009^{*}$ & 0.046 & $0.253^{*}$ & 0.000 & 1 \\
\hline
\end{tabular}

Fang (2006) argued that the structure of household consumption will change rapidly during the 10 years after the GDP per capita exceed US\$1000. In China this happened for the first time in 2003 while the consumption expenditure per capita of urban residents surpassed $¥ 6000$ in that same year. Therefore, from the perspective of consumption, we assume that $¥ 6000$ per capita is the inflection point of the evolution of Chinese urban residents' ECF and this is tested below.

When $\left\{\begin{array}{l}D=0, x<0.6 \\ D=1, x \geq 0.6\end{array}\right.$, the coefficients $b_{1}$ and $b_{2}$ are simultaneously significant (Table 1 ), and $¥ 6000$ is

the inflection point of the gross per-capita ECF. Hence there is a non-linear relationship between emissions intensity and consumer spending. We let b1 stand for emissions intensity below the inflection point, and let $\mathrm{b}+\mathrm{b} 2$ stand for emissions intensity beyond the inflection point. Table 1 shows that the coefficient b1 is positive, so the emissions intensity will increase when the expenditure are beyond the inflection point. 
According to Lescaroux (2011), energy consumption follows an S-curve with income per capita increasing, and energy intensity follows a bell-shaped curve. The $¥ 6000$ inflection point is in the left half of the bell curve, leaving further room for emissions intensity to increase. The structure of ECF is represented by: $E C F_{i}$ $=\alpha_{l}+\beta_{l} D_{i}+b_{i 1} D_{i} x+b_{i 2} x+\varepsilon_{l} \quad$ (6) where $i$ stands for consumption of food, housing etc.

- Assume $¥ 6000$ to be the inflection point: We can define a dummy variable that $\left\{\begin{array}{l}D_{i}=0, x<0.6 \\ D_{i}=1, x \geq 0.6\end{array}\right.$

The coefficients $b_{i 1}$ and $b_{i 2}$ are simultaneously significant for the equations of food, clothing, recreation, communication and education ECFs (Table 2), which means that $¥ 6000$ is the first inflection point for them. The emissions intensity will change, when the expenditure exceeds the inflection point. As $b_{i l}$ is negative in the food and clothing ECFs, the emissions intensity of food/clothing will decrease when the expenditures are beyond the $¥ 6000$ inflection point. With an overall upward trend in consumer demand, food and clothing consumption is mainly related to subsistence. Their shares will be reduced with increasing income.

Table 2. Regression Results of ECF per Capita (Inflection Point $=6000, * \mathrm{p}<.05$ )

\begin{tabular}{|l|c|c|c|c|c|}
\hline & \multicolumn{2}{|c|}{$b_{i 1}$} & \multicolumn{2}{c|}{$b_{i 2}$} & \multicolumn{2}{c|}{$\begin{array}{c}\text { Adjusted } \\
\text { R Square }\end{array}$} \\
\cline { 2 - 5 } & $\begin{array}{c}\text { Unstandardized } \\
\text { Coefficients }\end{array}$ & Significance & $\begin{array}{c}\text { Unstandardized } \\
\text { Coefficients }\end{array}$ & Significance \\
\hline Food ECF & $-0.027^{*}$ & 0.009 & $0.050^{*}$ & 0.000 & 0.931 \\
\hline Clothing ECF & $-0.008^{*}$ & 0.018 & $0.029^{*}$ & 0.000 & 0.987 \\
\hline Housing ECF & -0.005 & 0.335 & $0.067^{*}$ & 0.000 & 0.995 \\
\hline Transport ECF & $0.049^{*}$ & 0.002 & 0.018 & 0.232 & 0.954 \\
\hline Recreation ECF & $0.019^{*}$ & 0.005 & $0.033^{*}$ & 0.000 & 0.989 \\
\hline Health and hygiene ECF & -0.009 & 0.055 & $0.029^{*}$ & 0.000 & 0.978 \\
\hline Communication ECF & $-0.006^{*}$ & 0.017 & $0.017^{*}$ & 0.000 & 0.977 \\
\hline Education ECF & $-0.005^{*}$ & 0.001 & $0.011^{*}$ & 0.000 & 0.976 \\
\hline
\end{tabular}

The coefficient $b_{i l}$ is positive for entertainment ECF, ie the emissions intensity of leisure and entertainment increases when expenditure is beyond the $¥ 6000$ inflection point. Recreation is enjoyment-oriented consumption and when GDP per capita reaches US\$800 to 1000 , this consumption enters a period of rapid growth. Also, the Chinese governments have reformed the leave system. The ratio of working days and holidays reached 241:114, compared to 305:60 previously, leisure days now account for 31\%, of the year generating demand for leisure and entertainment. The $b_{i l}$ coefficient is negative for communication ECF, indicating that communication is a basic demand in China nowadays with the information industry well developed. The supply of information products and services, including mobiles, is sufficient and the price is low. Chinese also pay attention to "favor association". Formal and informal communications between people are frequent. The $b_{i 1}$ coefficient is negative for education ECF. China has always had a fine tradition of emphasis on education and people believe that this is the last thing to sacrifice. The intense employment competition urged further spending on education recently. Especially for low-income households, it can change the family's fate. On the other hand, the one-child policy made people concentrate on this child's education. For high-income families however the emissions intensity of education will be relatively lower.

- Assume $¥ 8000$ to be the inflection point: The dummy variables are redefined as follows $\left\{\begin{array}{l}D_{i}=0, x<0.8 \\ D_{i}=1, x \geq 0.8\end{array}\right.$

In addition to the equations of the food, clothing, recreation communication and education ECFs, ¥8000 is the inflection point of transport and health and hygiene ECF equations, and is their first inflection point (Table 3). The $b_{i l}$ coefficient is $>0$ for transport, which indicates that the emissions intensity will increase when the expenditures are beyond $¥ 8000$. With the acceleration of the pace of life, modern transport rapidly becomes essential for households. The growing middle class has a strong desire to own cars, a status symbol in China. Health and hygiene account for $10 \%$ of total ECF and keep stable. The relatively larger inflection point value indicates that the consumption of health and hygiene covers a longer duration. As living standards improve, people's health consciousness increases and various healthcare equipment and medical services enter the household. The healthcare system reform however shifted the burden of medical expenses to the individual.

Table 3. Regression Results of ECF per Capita (Inflection Point $=8000,{ }^{*} \mathrm{p}<.05$ )

\begin{tabular}{|l|c|c|c|c|c|}
\hline & \multicolumn{2}{|c|}{$b_{i 1}$} & \multicolumn{2}{c|}{$b_{i 2}$} & \multirow{2}{*}{$\begin{array}{c}\text { Adjusted } \\
\text { R Square }\end{array}$} \\
\cline { 2 - 6 } & $\begin{array}{c}\text { Unstandardized } \\
\text { Coefficients }\end{array}$ & Sig. & $\begin{array}{c}\text { Unstandardized } \\
\text { Coefficients }\end{array}$ & $0.044^{*}$ & 0.000 \\
\hline Food ECF & $-0.023^{*}$ & 0.000 & $0.028^{*}$ & 0.037 \\
\hline Clothing ECF & $-0.007^{*}$ & 0.000 & $0.066^{*}$ & 0.000 & 0.988 \\
\hline Housing ECF & -0.005 & 0.066 & 0.995 \\
\hline
\end{tabular}




\begin{tabular}{|l|l|l|l|l|l|}
\hline Transport ECF & $0.053^{*}$ & 0.000 & $0.022^{*}$ & 0.000 & 0.974 \\
\hline Recreation ECF & $0.014^{*}$ & 0.000 & $0.038^{*}$ & 0.000 & 0.989 \\
\hline Health and hygiene ECF & $-0.012^{*}$ & 0.000 & $0.030^{*}$ & 0.000 & 0.987 \\
\hline Communication ECF & $-0.006^{*}$ & 0.000 & $0.016^{*}$ & 0.000 & 0.982 \\
\hline Education ECF & $-0.004^{*}$ & 0.000 & $0.010^{*}$ & 0.000 & 0.976 \\
\hline
\end{tabular}

- Assume $¥ 10000$ to be the inflection point: the dummy variables are redefined as follow: $\left\{\begin{array}{l}D_{i}=0, x<1.0 \\ D_{i}=1, x \geq 1.0\end{array}\right.$

Table 4. Regression Results of ECF per Capita (Inflection Point $\left.=10000 *{ }^{*} \mathrm{p}<.05\right)$

\begin{tabular}{|l|c|c|c|c|c|}
\hline & \multicolumn{2}{|c|}{$b_{i 1}$} & \multicolumn{2}{c|}{$b_{i 2}$} & \multirow{2}{*}{$\begin{array}{c}\text { Adjusted } \\
\text { R Square }\end{array}$} \\
\cline { 2 - 5 } & $\begin{array}{c}\text { Unstandardized } \\
\text { Coefficients }\end{array}$ & Significance & $\begin{array}{c}\text { Unstandardized } \\
\text { Coefficients }\end{array}$ & Significance & \\
\hline Food ECF & $-0.022^{*}$ & 0.000 & $0.041^{*}$ & 0.000 & 0.940 \\
\hline Clothing ECF & $-0.007^{*}$ & 0.000 & $0.027^{*}$ & 0.000 & 0.988 \\
\hline Housing ECF & $-0.006^{*}$ & 0.014 & $0.065^{*}$ & 0.000 & 0.996 \\
\hline Transport ECF & $0.055^{*}$ & 0.000 & $0.025^{*}$ & 0.000 & 0.978 \\
\hline Recreation ECF & $0.012^{*}$ & 0.000 & $0.042^{*}$ & 0.000 & 0.988 \\
\hline Health and hygiene ECF & $-0.013^{*}$ & 0.000 & $0.030^{*}$ & 0.000 & 0.989 \\
\hline Communication ECF & $-0.006^{*}$ & 0.000 & $0.016^{*}$ & 0.000 & 0.981 \\
\hline Education ECF & $-0.003^{*}$ & 0.000 & $0.010^{*}$ & 0.000 & 0.977 \\
\hline
\end{tabular}

Table 4 shows that $¥ 10000$ is the inflection point and the first inflection point for housing in addition to the former seven equations and is the largest among all equations. The value of housing consumption is large, it takes long for urban residents to accumulate funds to own a home, so the improvement in housing penetration is slow. Its $b_{i l}$ coefficient is $<0$ indicating that to some extent the housing reform has released a pulling effect of basic housing needs. We forecast that improvement-oriented housing purchase will soon become a consumption hotspot. The absolute value of $b_{i l}$ only accounts for $10 \%$ of $b_{i 2}$, indicating that household emissions intensity will keep stable.

- Expenditure elasticity of ECFs: Expenditure and income have been found to be the strongest predictors of household energy requirements or environmental impacts (Lenzen et al. 2004; Reinders et al. 2003). We test a common model form to estimate the expenditure elasticity $\varepsilon_{\imath}$ of ECFs, defined as:

$$
\varepsilon_{i}=\frac{\bar{x}}{\overline{E C F}_{i}} b_{i}
$$

Table 5. Expenditure Elasticities of ECFs

\begin{tabular}{|l|c|c|}
\hline & $\mathcal{E}_{i}<¥ \mathbf{1 0 0 0 0}$ & $\varepsilon_{i}>¥ \mathbf{1 0 0 0 0}$ \\
\hline Food ECF & 0.677 & 0.463 \\
\hline Clothing ECF & 1.191 & 0.875 \\
\hline Housing ECF & 0.925 & 0.893 \\
\hline Transport ECF & 1.768 & 2.122 \\
\hline Recreation ECF & 1.607 & 1.341 \\
\hline Health and hygiene ECF & 1.003 & 0.644 \\
\hline Communication ECF & 1.243 & 0.792 \\
\hline Education ECF & 0.766 & 0.762 \\
\hline
\end{tabular}

All expenditure elasticities of ECFs are greater than zero. When the expenditure is below the $¥ 10000$ inflection point, the expenditure elasticities of clothing, transport, recreation, health and communication ECFs are greater than 1, indicating that those are "luxury" emissions. When the expenditure is beyond the inflection point, the expenditure elasticity of the transport, recreation and housing ECFs is larger, in which the former two are more than 1, so the transport and recreation ECFs belong to "luxury" emission. In all consumptions, only the transport ECF expenditure elasticity beyond the $¥ 10000$ inflection point is larger than that below the inflection point. Those show that "luxury" emissions are relative and therefore we need to focus on them.

The analysis shows that the emission intensities of Chinese urban residents' consumption still have room for growth, which stems from improvement in the consumption structure. Two types of consumption emissions are important: (1) the value of the first inflection is larger, and (2) the "luxury" emissions beyond the $¥ 10000$ inflection point. Accordingly, transport, housing, and recreation consumptions are these areas of focus.

\section{CONCLUSION}

This analysis shows that the ECF structure is stable; the food and housing ECFs are dominant when consumption expenditure is below $¥ 6000$. When consumption expenditure is beyond $¥ 10000$, the ECF structure changes: food, clothing and other survival-oriented emissions intensity as well as education, health and other development-oriented emissions intensity reduces; transport, recreation, housing and other enjoyment-oriented emissions intensity increases or remains stable; the total emissions intensity increases. The current per capita consumption expenditure of Chinese urban residents exceeds $¥ 10000$ and the low-income class is in the $¥ 6000$ range. China is moving towards high-carbon consumption.

- Enjoyment-oriented consumption: The share of the housing ECF is larger at $30 \%$ of total ECF and is 
relatively stable. Its first inflection point value is the largest. Hence housing should be the focal point in reduction policies. The expenditure elasticity of transport ECF is $>1$ below and beyond the $¥ 10000$ inflection point. As the current per capita expenditure of urban residents has entered the $¥ 10000$ range, transport consumption should be at the core of carbon-reduction policies. Recreational consumption is considered green but the ECF calculations show that it also generate a lot of "invisible" carbon emissions. In particular, when the expenditure level reaches $¥ 6000$, the emissions intensity of entertainment will rise rapidly.

- A consumption-based $\mathrm{CO}_{2}$ emissions quota system: There are close relationships between personal emissions and consumption patterns and a gap between consumer classes. A fair consumption-based $\mathrm{CO}_{2}$ emissions quota system can be built: each person is given a certain quota of $\mathrm{CO}_{2}$ emissions, and $\mathrm{CO}_{2}$ emissions credits can be traded in the secondary market. Aggregate emissions targets can determine the sum of rights to emit. In such a system each commodity has an ECF tag. The system allows people to realize the direct result of their consumption and to internalize the social costs of their actions. The price mechanism can be used to guide families to choose low-carbon consumption patterns. The poor whose expenditures are in the low level, could buy the products of higher ECF at a lower price. For the rich, in order to consume more goods and services, they have to buy the products of lower ECF but at a higher price.

China has entered the total emissions control era. Establishing a consumption-based $\mathrm{CO}_{2}$ emissions quota system can assist the government in this but further studies are required for its successful implementation.

\section{ACKNOWLEDGEMENT}

The last three authors acknowledge the financial help of the Australian Research Council.

\section{REFERENCES}

Abrahamse W., L. Steg (2009). How do socio-demographic and psychological factors relate to households' direct and indirect energy use and savings? Journal of Economic Psychology, 30: 711-720.

Adua L. (2010). To cool a sweltering earth: Does energy efficiency improvement offset the climate impacts of lifestyle? Energy Policy, 38: 5719-5732.

Benders R.M.J., R. Kok, H.C. Moll, G. Wiersma and K.J. Noorman (2006). New approaches for household energy conservation-In search of personal household energy budgets and energy reduction options. Energy Policy, 34: 3612-3622.

Bicknell K.B., R.J. Ball, R. Cullen, H.R. Bigsby (1998). New methodology for the ecological footprint with an application to the New Zealand economy. Ecological Economics, 27: 149-160.

Druckman A. and T. Jackson (2009). The carbon footprint of UK households 1990-2004: A socio-economically disaggregated, quasi-multi-regional input-output model. Ecological Economics, 68: 2066-2077.

Fang A. (2006). Chinese consumer demand trends and consumer policy research. China Economic Publishing House. Beijing.

Ferng J. (2001). Using composition of land multiplier to estimate ecological footprints associated with production activity. Ecological Economics, 37: 159-172.

International Energy Agency (IEA) (2008). World Energy Outlook, OECD, Paris.

Lenzen M., D. Christopher and F. Barney (2004). Energy requirements of Sydney households. Ecological Economics, 49: 375-399.

Lenzen M. and M.A. Shauna (2001). A modified ecological footprint method and its application to Australia. Ecological Economics, 37: 229-255.

Lescaroux F. (2011). Dynamics of final sectoral energy demand and aggregate energy intensity. Energy Policy, 39: 66-82.

National Bureau of Statistics of China (NBSC) (2003-2009). China Urban life and price Yearbook (2003-2009), China Statistics Press, Beijing.

National Bureau of Statistics of China (NBSC) (2007). 2006 China Energy Statistical Yearbook, Energy Bureau of Statistics Press and China Statistics Press, Beijing.

Reinders A.H.M.E., K. Vringer and K. Blok (2003). The direct and indirect energy requirement of households in the European Union. Energy Policy, 31: 139-153.

Rood G.A., J.P.M. Ros, E. Drissen and K. Vringer (2003). A structure of models for future projections of environmental pressure due to consumption. Journal of Cleaner Production, 11: 491-498.

Wackernagel, M. and W. Rees (1996), Our Ecological Footprint: Reducing Human Impact on the Earth, New Society Publishers, Gabriola Island, BC

Weber C.L. and H.S. Matthews (2008). Quantifying the global and distributional aspects of American household carbon footprint. Ecological Economics, 66: 379-391. 